\title{
O ESTADO DA ARTE: CONSTRUCIONISMO SOCIAL E A PERFORMANCE TERAPÊUTICA NO BRASIL
}

\author{
THE STATE OF ART: SOCIAL CONSTRUCTIONISM AND THE THERAPEUTIC \\ PERFORMANCE IN BRAZIL
}

\section{TAFFAREL RAMIRES FERNANDES ${ }^{1}$}

\section{VINÍCIUS AMARANTE NASCIMENTO 2}

${ }^{1}$ Centro Universitário FIPMoc, Montes Claros, MG, Brasil

2 Universidade Estadual de Montes Claros, MG, Brasil
RESUMO: Este estudo de revisão propôs o mapeamento da produção de artigos científicos referentes à clínica psicoterápica construcionista social. A partir do método bibliográfico denominado "Estado da arte", foi realizado um levantamento de artigos científicos publicados na plataforma virtual Biblioteca Virtual de Saúde - Psicologia (BVS-PSI) e Scientific Electronic Library Online (SciELO). Obteve-se como resultado a coleta de 09 artigos que, posteriormente à leitura na íntegra, foram organizados em 03 eixos temáticos: abordagens teóricas, narrativas sobre o terapeuta e 0 conceito de self. Esse processo de estudo evidenciou a orientação do construcionismo social para a constituição de uma prática clínica colaborativa em que o terapeuta atua de maneira reflexiva, dialógica e engajada.

PALAVRAS-CHAVE: Construcionismo social; Psicoterapia; Terapeuta.
ABSTRACT: The present review intended to propose the mapping of scientific articles that refer to the Social Constructionist psychotherapeutic clinic. From the bibliographic method called "State of art", a survey on scientific articles, published in the virtual platforms Biblioteca Virtual de Saúde - Psicologia (BVS-PSI) and Scientific Electronic Library Online (SciELO), was carried out. As a result, 09 articles were collected, which after been read in full, were organized into 03 thematic axes: theoretical approaches, narratives about the therapist and the concept of self. This study process evidenced the orientation of social constructionism to the constitution of a collaborative clinical practice in which the therapist acts in a reflexive, dialogic and engaged way.

KEYWORDS: Social Constructionism; Psychotherapy; Therapist.

\section{INTRODUÇÃo}

A esperança é que a presente discussão possa contribuir para a geração de conversas, um amadurecimento das sensibilidades e o surgimento de novas práticas.

Gergen \& Ness (2016, p. 504)

Recebido em: 24/03/2019 Aprovado em: 10/06/2019 ta imbricação de discursos o construcionismo social desponta não como uma
metanarrativa, mas enquanto um movimento, dinâmico, criativo e inovador;

O construcionismo social, entendido enquanto movimento social recente no Brasil e de grande destaque internacional, é, como apontam Rasera e Japur (2005), de difícil definição, visto que possui múltiplos discursos produzidos a seu respeito, tanto no campo epistemológico quanto no campo científico. Nes- 
perpassado por diversas vozes que produzem inteligibilidades.

Tendo conhecido esse discurso por meio da Terapia Familiar que, por sua vez, é um dos meios pelos quais o construcionismo social historicamente se incorporou à clínica, como afirmam Martins, Santos e Rasera (2013), a presente pesquisa surgiu do desejo do primeiro autor, ainda na graduação em Psicologia, que buscava promover atendimentos psicoterápicos, na clínica do serviço-escola, em consonância com a postura polivocal, crítica e dialógica do construcionismo social.

Isto se deu de modo coerente com a finalidade do serviço-escola. Conforme Amaral et al. (2012), o serviço-escola possui função de ofertar condição de treinamento clínico para os alunos e prestar serviço psicológico à comunidade. Sendo assim, para aquele que inicia a prática clínica com o desejo de se orientar pelo instrumental epistemológico do construcionismo social, o levantamento bibliográfico concernente a esta prática se impõe como condição de possibilidade para a performance terapêutica.

Neste contexto originário identificou-se o objetivo central desta pesquisa: "mapear a produção de artigos científicos sobre psicoterapia de orientação construcionista social no Brasil". Esse tipo de documentação é entendido como práticas discursivas materialmente expressas em bancos de dados de domínio público.

Aqui entendemos práticas discursivas como linguagem em ação, em constante movimento, e constituída por três elementos principais: a dinâmica, ou seja, os enunciados orientados por vozes; as formas, os gêneros textuais; e os conteúdos, que são os repertórios interpretativos (Spink \& Medrado, 2013).
Concordando com Spink, Ribeiro, Conejo, e Souza (2014), entendemos que documentos de domínio público são, em termos conversacionais, tudo o que faz parte de um mesmo fluxo de ideias, propostas, argumentos e sentidos, cujas materialidades e socialidades também se transformam no tempo. Dessa forma, no bojo do movimento construcionista, analisar os artigos científicos publicados em revistas indexadas é forte impulsionador para novas reflexões.

Ainda referenciando os autores acima citados, "os documentos de domínio público são - em si mesmos produtos sociopolíticos de uma ideia radical: a própria noção do público enquanto esfera de ação e discussão, um lugar onde é possível ter e expressar opiniões" (Spink et al., 2014, p. 213). É neste ensejo que o presente artigo se insere na esfera pública da produção acadêmica, enquanto escolha metodológica, para extrair dados específicos sobre a performance terapêutica construcionista social no Brasil, e, tornando também esta pesquisa pública, se insere na dinâmica crítica, reflexiva e em permanente movimento do campo epistemológico construcionista.

Esta pesquisa se mostra relevante por se debruçar sobre um compilado de artigos publicados em revistas indexadas, disponibilizadas em plataformas virtuais de grande alcance e relevância na formação de acadêmicos e profissionais da Psicologia, bem como meio de reflexão e crítica, vitais ao movimento construcionista social.

Dessa maneira, socialmente se encontra grande importância em produzir um discurso aberto e polifônico, capaz de produzir múltiplas realidades, pois se insere na gama de práticas discursivas que viabilizam uma postura psicoterápica social- 
mente engajada, dialógica e situada em seu contexto histórico.

Para alcançar este propósito, trabalhou-se com um estilo exploratório qualitativo, de caráter bibliográfico. $\mathrm{O}$ método de mapeamento bibliográfico denominado "Estado da Arte" foi empregado, pois objetiva analisar as publicações em determinada área. Tal instrumento metodológico possibilita evidenciar os tópicos específicos, novas ideias, métodos e subtemas que têm recebido maior ou menor ênfase na literatura selecionada (Vosgerau \& Romanowski, 2014).

Romanowski e Ens (2006) afirmam que, embora recentes, os estudos de "estado da arte" que objetivam a sistematização da produção numa determinada área do conhecimento já se tornaram imprescindíveis para apreender a amplitude do que vem sendo produzido nos diversos campos do conhecimento.

Para Vosgerau e Romanowski (2014), ao referenciar Soares e Maciel (2000), aquele que recorre à pesquisa do tipo Estado da Arte deve considerar ao longo do trabalho as categorias que identifiquem, em cada texto e no conjunto deles, as facetas sobre as quais o fenômeno vem sendo analisado.

Justifica-se utilizar este método pois ele garante uma visão geral do que vem sendo produzido na área $\mathrm{e}$ uma ordenação que permite aos interessados perceberem a evolução das pesquisas na área, bem como suas características e foco, além de identificar as lacunas ainda existentes (Romanowski \& Ens, 2006).

Conforme Mirim (2004, pp.155156), "garimpando sentidos em bancos de dados" é possível, ao pesquisador, acessar as produções científicas cristalizadas, e a bibliografia levantada é compreendida como "discursos peculiares a um estado específico da sociedade".
Segundo a mesma autora, "a construção de variadas e sucessivas estratégias de pesquisa e a análise de seus resultados contribui para a elaboração da estratégia que elegemos para acessar referências bibliográficas valiosas (segundo nossos critérios) para este estudo" (Mirim, 2004, p.158).

Com esse entendimento, recorremos à Biblioteca Virtual de Saúde Psicologia (BVS-Psi) e ao portal Scientific Electronic Library Online (SciELO) para a obtenção de artigos em português, publicados até o primeiro semestre de 2018, a partir da relação entre os descritores: construcionismo social, psicoterapia, terapia e clínica.

A estratégia de busca utilizada foi a de ter o descritor construcionismo social como base e aplicar entre ele e os demais descritores, alternadamente, a conjunção aditiva "and" (construcionismo social "and" psicoterapia, construcionismo social "and" terapia e construcionismo social "and" clínica). A seleção dos artigos foi feita manualmente e suprimidos aqueles: repetidos, em inglês, que tratavam de práticas de terapia grupal, que não tratavam de áreas de atuação do profissional psicólogo, livros, entrevistas, anais de evento e, suprimidos também, resumos sem o artigo em sua integralidade.

Foram apurados 233 artigos; deste montante, após leitura dos resumos, chegamos a um total de nove artigos publicados entre 2003 e 2017, originais, de caráter descritivo, síntese-interpretativos e revisão e relatos de experiência que atendiam ao objetivo desta pesquisa. Destaca-se a grande relevância da revista Nova Perspectiva Sistêmica, publicada pelo Instituto Noos, em propiciar espaço de publicação de trabalhos com esta temática, pois publicou seis dos nove artigos selecionados. As revistas Estudos de Psicologia - UFRN, Estudos de Psico- 
logia - PUC-Campinas e Psicologia: teoria e pesquisa - UNB publicaram um artigo.

Os artigos resultantes da seleção, após realizada a leitura na íntegra e a partir do objetivo deste trabalho, foram agrupados por semelhança em eixos temáticos, a saber: "propostas terapêuticas" (5), "narrativas sobre o terapeuta" (3) e "o conceito de self" (1).

Esta organização por eixos temáticos condiz com o objetivo de se evidenciar os discursos que emergem da articulação dos descritores escolhidos segundo problema proposto na pesquisa. Após estes serem organizados por similaridade temática, buscou-se, na pesquisa, detalhar os procedimentos utilizados pelos autores para apresentar e sustentar suas análises.

\section{PROPOSTAS TERAPÊUTICAS}

Rasera e Japur (2005, p.22), ao referenciarem Burr (1995), apresentam a complexidade de se tentar falar do construcionismo social enquanto pensamento único, idêntico a si mesmo, visto que, pela sua característica performática, crítica e não ontológica, os autores considerados construcionistas possuem entre si somente uma "semelhança familiar".

Estes autores seguem se referenciando a Burr (1995) para inferir que o surgimento do construcionismo se deu em 1973, com a publicação do artigo Social psychology as history, de Kenneth Gergen. Ao retomarem Gergen (1985), que diz que o construcionismo é um movimento, os autores se remetem ao princípio de que este é efeito de múltiplos processos que o antecederam.

Ainda recorrendo a Gergen (1995), Rasera e Japur (2005, p.22) apresentam que "o construcionismo está inserido no contexto do desenvolvimento da ciência" e destacam as três principais críticas ao fazer científico: "a crítica social, a ideológica e a retórico-literária”. Sendo assim, os autores concluem que "é no bojo do pensamento pautado por essas críticas que emerge o construcionismo".

Diante do exposto, entende-se que variados pesquisadores apresentaram propostas terapêuticas que compartilham de perspectivas comuns, confluentes à perspectiva construcionismo social, diferenciando-se de outras perspectivas que possuem um autor primário do qual outros derivam.

Contudo, mesmo havendo certa familiaridade entre as propostas teóricas, estas também possuem distinções e tensionamentos entre si. Dados os limites deste trabalho, apresentaremos a relação das perspectivas teóricas relativas à prática clínica com sucinta descrição, conforme os artigos mapeados e congregados neste eixo específico.

As perspectivas teóricas identificadas serão apresentadas sem uma ordem hierárquica ou de preferência: (a) Terapia Narrativa - Michael White e David Epston, (b) Abordagem Colaborativa - Harlene Anderson, (c) Processos Reflexivos - Tom Anderson, (d) Terapia Focada na Solução - Steve de Shazer, (e) Terapia Social Newman Holzman.

A primeira, Terapia Narrativa, descrita em um artigo originalmente publicado por J. Winslade e G. Monk, na revista alemã Familien dynamik em julho de 2011, teve sua versão em português publicada em 2016 na revista Nova Perspectiva Sistêmica, com o título "Mediação Narrativa: uma abordagem diferenciada para a resolução de conflitos".

Por meio de um estudo epistemológico, os autores tiveram como objetivo principal mostrar como a criação 
de um novo espaço relacional, usando o método narrativo, gera o ambiente para a obtenção de um entendimento mútuo. Estes concluíram que a mediação narrativa é um recurso útil para a solução de conflitos de forma satisfatória, bem-sucedida e que ainda leva os sujeitos a construírem compromissos duradouros.

Os autores afirmam que o pressuposto da narrativa é que sempre existem elementos subjacentes em uma história esperando serem reconhecidos. Com este entendimento, pode-se desenvolver uma escuta do que é dito e do que está subliminarmente expresso, possibilitando a emersão de uma contra-história, regida por novos enredos.

No segundo artigo, "Terapia narrativa e abordagem colaborativa: contribuições do construcionismo social para a clínica pós-moderna", Brito e Germano (2013), por meio de uma análise comparativa, investigam as relações de aproximação e distanciamento entre a Terapia Narrativa e a abordagem colaborativa (que será tratada posteriormente), tendo como pano de fundo comum o construcionismo social. Estes concluem que o socioconstrucionismo é base epistemológica destas práticas e aponta transformações da psicoterapia, pois o psicólogo passa a ser entendido como coautor de histórias na clínica.

Conforme Brito e Germano (2013), a Terapia Narrativa teve origem anos 1980 com o australiano, assistente social e terapeuta familiar Michael White (1948-2008) e com David Epston, antropólogo, sociólogo e terapeuta familiar, nascido em 1944, no Canadá, que atualmente é diretor do The Family Therapy Center e leciona na Escola de Estudos Sociais do Instituto de Tecnologia, em Auckland, Nova Zelândia.

Estes, influenciados pelo método interpretativo das ideias sistêmicas de Bateson, compreendem que não se pode conhecer a realidade de forma objetiva, e sim de forma interpretativa pelos significados que as pessoas lhe atribuem. Há uma ênfase nas histórias de vida e nas diferenças que podem ser alcançadas quando a pessoa conta e reconta sua história, separando-se a pessoa do problema e potencializando narrativas alternativas às dominantes.

Os autores do referido artigo apontam que a terapia narrativa é marcada por sua ênfase na desconstrução de histórias dominantes e na ampliação das possibilidades de diálogo e construção de significados, pois, concordando com o construcionismo social quando destaca que o mundo não é reflexo de nossas interpretações, mas um artefato social, afirmam que nenhuma realidade está previamente dada; os problemas são construções sociais possibilitadas por um contexto específico.

Uma segunda perspectiva, desenvolvida por Harlene Anderson e Harold Goolishia, por volta dos anos 1980, é a Abordagem Colaborativa. Brito e Germano (2013) destacam que os seus precursores tiveram por influência a Terapia Familiar e que concebem o sistema terapêutico como linguístico formado em torno de um problema, mas que suas características são atribuições daqueles envolvidos, podendo, portanto, ser negociadas e alteradas no campo da linguagem em uso. Rasera e Japur (2004) referem-se a esta perspectiva como "uma das tentativas mais explícitas de construção de um modo de fazer psicologia construcionista”.

Brito e Germano (2013) destacam a característica antiessencialista do construcionismo social e sua correspondência na abordagem colaborativa. Apontam que se os problemas estão na linguagem, deve-se pôr atenção aos 
múltiplos significados e versões que podem ser conferidos a certos eventos e situações por um mesmo narrador. Dessa maneira, segundo os autores, os problemas deixam de ter uma existência objetiva, como propugnado por vertentes da psicologia, e passam a ser entendidos como efeito de um sentido criado pela via da linguagem.

A descrição dessa abordagem é concluída no artigo em questão, com a compreensão de que a terapia colaborativa não atua com métodos previamente definidos, certezas, nem uma solução certa e que deverá ser desvelada, mas atua com o diálogo, o manejo de sentidos, em que terapeuta, fora de uma posição hierarquicamente superior, e cliente, concebido como especialista de sua vida, se empenha em abrir o diálogo no intuito de trazer à tona novas possibilidades.

Sobre Processos Reflexivos, Rasera e Japur publicaram em 2004, na revista Estudos em Psicologia - UFRN, o artigo intitulado "Desafios da aproximação do construcionismo social ao campo da psicoterapia". Neste trabalho, analisou-se minuciosamente as propostas da terapia narrativa de White e Epston, da abordagem colaborativa de Harlene Anderson e dos processos reflexivos de Tom Andersen. As conclusões, aqui apresentadas sucintamente, dão conta de que as propostas terapêuticas estão em consonância com o construcionismo social e as redimensionam para além de técnicas, mas opções discursivas.

Visto que o artigo trata de duas abordagens teóricas já mencionadas, aqui será enfocado brevemente o que apontam sobre os Processos Reflexivos. Proposto por Tom Anderson, como afirmam Rasera e Japur (2004), os Processos Reflexivos são mais uma maneira de pensar que uma proposta terapêutica. Nessa perspectiva, é for- mada uma equipe que atua conjuntamente com o cliente sobre seu caso, produzindo, assim, um diálogo aberto, não hierarquizado e unidirecional, com vistas a abrir o processo de produção de sentidos.

Os autores afirmam que, para Andersen, as ideias principais que norteiam esta abordagem são: a negação da existência de uma coisa como algo em si, a existência de diferenças que produzem efeitos diversos tanto para não ocorrer mudanças, quanto para a abertura ou fechamento à mudança. Andersen concebe a constituição de uma pessoa como estruturalmente forte e em mudança, delimitada por suas possibilidades estruturais; concebe que devido às diferentes formas de se autodescrever, existe uma multiplicidade de pessoas em cada um, consequentemente, pela diversidade discursiva pela qual cada pessoa é perpassada, a conversa terapêutica adquire ênfase polivocal.

A quarta proposta psicoterápica, a Terapia Focada na Solução, foi localizada no artigo "A terapia focada na solução e suas aproximações ao discurso construcionista social", de autoria de Martins, Santos e Rasera (2013), publicado pela revista Estudos em Psicologia - PUC-Campinas. Seu objetivo foi o de identificar as relações entre o discurso construcionista e os conceitos e práticas da terapia Focada na Solução. Após criteriosa análise conceitual e comparativa de bibliografia selecionada, os autores consideram a Terapia Focada na Solução como uma opção discursiva útil, mas com pontos de divergência com o construcionismo.

Conforme apresentam Martins et al. (2013, p. 112), a Terapia Focada na solução encontra-se "inserida no contexto da terapia familiar sistêmica, cujo foco está voltado para as possibi- 
lidades e competências do cliente". Seu principal autor, Steve Shazer (19402005), propôs "deslocar a atenção destinada aos problemas para as possibilidades, em que essas são possibilidades de construção de discursos alternativos àqueles nos quais o problema é central" (Martins et al., 2013, p. 118). Dessa forma, a busca por soluções se dá pela via das potencialidades do cliente e da sua capacidade de criar novos significados.

Conforme os autores, identifica-se uma postura de flexibilidade frente à relação entre as verdades sobre o mundo empírico e o funcionamento humano, em que o terapeuta busca percorrer as diversas possibilidades úteis ao processo terapêutico; isso leva a um deslocamento da noção essencialista para a consciência da construção. Entretanto, na busca por se alcançar a solução para o problema enfocado, o terapeuta passa a ter uma postura diretiva e de especialidade que determina o percurso que a conversa deve tomar para se alcançar a mudança comportamental almejada.

Nesse sentido os autores ainda acrescentam que o construcionismo convida a terapia focada na solução a fazer uma passagem da postura de especialidade do terapeuta para outra de colaboração, em que diferentes saberes são utilizados na medida em que colaboram com a sessão, o que desloca o terapeuta da postura neutra e destituída de valores para uma postura comprometida com valores éticos e políticos.

No artigo "Diálogos entre o discurso construcionista social e a terapia social", a Terapia Social é apresentada por Manfrim e Rasera (2016) após analisar crítica e comparativamente obras da terapia social a partir das propostas construcionistas no que se refere à postura e práticas terapêuticas.
Estes autores inferem que os distanciamentos da Terapia Social podem ser entendidos como convites à reflexão e ao desenvolvimento teórico do construcionismo e da própria terapia.

A Terapia Social proposta por Newman e Holzman, como apresentam Manfrim e Rasera (2016, p. 36), põe ênfase na ação, o que "traduz o engajamento político e ativista que esta proposta busca incentivar". Segundo estes autores, Newman e Holzman foram influenciados pela filosofia da linguagem de Wittgenstein e Vygotsky, respectivamente; e conceberam o ativismo e o engajamento cotidiano como profícuos meios de transformação social.

Manfrim e Rasera (2016), ao referenciarem Holzman e Mendez (2003), apontam que a Terapia Social busca articular práticas que possibilitem uma aproximação cultural performática para o entendimento da vida humana e que as pessoas possam ser vistas como criadoras da cultura e de suas próprias vidas.

Conforme o objetivo de mapeamento de artigos científicos sobre psicoterapia de orientação construcionista social no Brasil, foi aplicado o critério de exclusão de artigos em idiomas que não fossem o português. Contudo, um artigo, localizado pelo resumo em português, estava integralmente em inglês, e este, fruto de uma pesquisa qualitativa, realizada por pesquisadores brasileiros, em uma universidade nacional, teve como objetivo analisar, após entrevistas semiestruturadas, o uso das teorias construcionistas por 14 psicoterapeutas em território brasileiro. Dada a relevância da pesquisa, apresentaremos a seguir alguns aspectos desta investigação.

$\mathrm{Na}$ pesquisa realizada por Paula Ravagnani, Guanaes-Lorenzi e Rasera (2017), intitulada "A utilização de 
modelos teóricos na Terapia Familiar: Foco no Construcionismo", publicada na revista Paidéia - USP-Ribeirão Preto, buscou-se entender como o construcionismo social é disseminado na prática clínica de psicoterapeutas da Terapia Familiar. Estes identificaram as seguintes categorias: (a) Conciliador-construcionista: se refere àqueles Terapeutas de Família que só usam estruturas teóricas relativas ao construcionismo social; (b) Conciliador-reflexivo: descreve aquele terapeuta que não utiliza somente as ideias de construção social em sua prática clínica; (c) Conciliador-explicativo: se refere ao terapeuta Familiar Sistêmico que faz uso de modelos teóricos do construcionismo na sua clínica; e, por fim, o (d) Eclético: remete aos terapeutas que recorrem a variados modelos explicativos, concomitantemente, para atender à demanda do cliente.

Por meio desta pesquisa, seus autores concluíram que a combinação de teorias busca enriquecer a prática clínica, ao mesmo tempo em que gera tensões no campo da Terapia Familiar. Os autores propõem ao terapeuta um aprofundamento na história da terapia familiar, suas rupturas e avanços, bem como uma reflexão e conscientização constante quanto ao seu modo de atuar, pois a congruência entre a prática empregada e as teorias subjacentes oferece uma postura que vai contra uma em que o terapeuta usa "o que funciona”.

\section{NARRATIVAS SOBRE 0 TERAPEUTA}

As narrativas sobre o terapeuta construcionista social concernentes aos três artigos referentes a esse eixo temático apresentam o profissional como aquele que adota uma postura colaborativa, engajando-se em um re- lacionamento dialógico, reflexivo, e que busca ter uma postura de não saber, sem julgamento e interpretações a priori.

Narra-se também que o terapeuta deve adotar uma postura poética social, em que sua atenção esteja voltada para os recursos linguísticos e culturais que abrem novas possibilidades na medida em que terapeuta e cliente se engajam na produção de conhecimento, além da postura de construção conjunta para o encontro com o outro (Martins, Silva, \& Guanaes-Lorenzi, 2014).

Dentro da seara construcionista, os artigos enfocam a "postura profissional" (Lenzi et al., 2015), a "formação de terapeutas" (Rosas \& Rapizo, 2011) e, ainda, o senso de competência de um terapeuta (Martins et al., 2014). Sem a pretensão de esgotar o tema, descreveremos brevemente os aspectos compreendidos como centrais nessas produções.

$\mathrm{O}$ artigo "A construção da postura profissional para o encontro terapêutico", publicado pela revista Nova Perspectiva Sistêmica em 2015, (Lenzi et al.) expõe como se dá a construção teórica e prática de uma postura profissional para a conversação terapêutica com pessoas e famílias, a partir de um relato de experiência. Os autores evidenciam o percurso traçado em um grupo de especialização em terapia familiar pós-moderna em que a teoria construcionista social e de práticas colaborativas foram profícuas na construção da postura profissional reflexiva, que abre para conversações.

Lenzi et al. (2015, p.07) concebem como necessário que o terapeuta consiga mais que utilizar técnicas, fazer a experiência de transformação pessoal a partir do engajamento em uma postura filosófica. Para tanto, afirmam que "é um intenso investimento na cons- 
trução da posição do terapeuta para o encontro conversacional, a partir das nossas histórias familiares e do processo de construção social de quem somos hoje". Com isso, os autores destacam a grande necessidade de os terapeutas terem conhecimentos dos discursos, narrativas que compõem sua história pessoal, para que, assim, possam efetivamente se engajar na narrativa que lhe chega pelo cliente.

Buscando estabelecer uma relação significativa entre terapeuta e cliente, os autores referenciam Shotter (1993) quando este destitui o terapeuta do lugar do "saber teórico" para o "saber desde". Nessa perspectiva, "saber desde" provoca o terapeuta a se deslocar da posição receptiva, intelectual, fria e distante, para uma postura de envolvimento com tudo que tem, não havendo possibilidade de se posicionar na conversação de forma neutra, mas sim ativo e imerso no processo do outro.

Referenciando McNamee e Gergen (1999), os autores ratificam a noção de que conversamos com os personagens internos que aparecem na narrativa do cliente, visando à ampliação das possibilidades de recursos para se enfrentar as dificuldades e o fortalecimento da autoria; isto implica uma "transformação da tradição de relação com outro absoluto, para um fluxo no diálogo de relação com os muitos dentro de nós" (Lenzi et al., 2015, p. 11).

Enfocando a postura do terapeuta no encontro com o cliente como uma relação de simetria e colaboração, Lenzi et al. (2015) retiram a ansiedade por uma interpretação sagaz do caso e perfeito uso de técnicas para destacar que terapeuta e clientes estão em uma relação onde ambos se colocam inteiramente em prol de construir algo novo.

Lenzi et al. (2015) reconhecem que a especialidade do terapeuta é a de possibilitar que o cliente encontre um ambiente no qual possa tecer um relacionamento significativo. Os autores, ao cunharem o aforismo o qual diz que o terapeuta é "anfitrião do cliente na terapia e gentil convidado em sua história" (Lenzi et al., 2015, p 14), demonstram, assim, como característica do terapeuta, o desejo por acolher gentil e empaticamente o cliente, bem como o respeito com aquela história de vida que se lhe apresenta.

Outro artigo importante nesta compreensão sobre a postura do terapeuta é o "Construcionismo Social e a formação de terapeutas: em busca de coerência”. Publicado em 2011, suas autoras, Rosas e Rapizo, discutiram sobre aspectos concernentes à formação de terapeutas de família sob a concepção construcionista social e dialógica. Segundo uma perspectiva atenta aos movimentos do seu tempo, destacam que a formação de terapeutas deve considerar a reflexão contínua e a coerência como uma busca incessante.

Para Rosas e Rapizo (2011, p. 63), a busca por coerência no processo de formação do terapeuta não é alcançável: "é mais um guia, uma diretriz para nosso constante movimento. Nunca chegamos lá". Com isso, resgatam a noção de que o terapeuta que recorre ao construcionismo social na sua atuação clínica deve conceber a realidade como discursiva, socialmente construída e relacional, o que, portanto, torna o processo formativo permanentemente em movimento e em transformação segundo seu contexto social e histórico.

As autoras recobram, ao citar Harper (2004), que o construcionismo não é uma teoria, mas uma moldura metateórica - uma teoria sobre teorias. Isso implica ter um horizonte claro a respeito dos sentidos que constituem o construcionismo social, mas também atenção para com seus movimentos, 
disposição crítica e abertura para as transformações. E completam que é na reflexividade conjunta e contínua, que não permite verdades estabelecidas, onde deve estar pautada a formação do terapeuta.

Rosas e Rapizo (2011, p. 63) afirmam que "o processo de busca de coerência entre a perspectiva construcionista, as práticas advindas dela e a formação de profissionais é contínuo e dinâmico" e que procuraram dar maior "ênfase à prática como base para a construção da teoria". Dessa maneira, vemos aplicada a premissa de que o construcionismo social, para além de uma teoria, é uma ferramenta que possibilita a construção de novas realidades.

Corrobora esta perspectiva o artigo "Os sentidos de uma intervenção e suas implicações para a construção do senso de competência de um terapeuta", de Martins, Silva e Guanaes-Lorenzi, publicado em 2014. Os autores objetivaram descrever como se deu a produção de sentidos com implicações na construção do senso de competência do terapeuta, concluindo que intervenções não possuem sentido em si mesmas, mas são realizações relacionais com potencial de utilidade em contextos situados e a autorreflexividade do terapeuta como recurso formativo.

Assim se afirma o caráter dialógico da terapia construcionista, no qual as pessoas ativamente constroem sentidos juntas, ao contrário de uma perspectiva utilitarista em que se recorre a técnicas para serem aplicadas. Deste modo, "o papel do terapeuta é, em conjunto e guiado pelo cliente, o de produzir inteligibilidades, relativizando e flexibilizando formas rígidas de significação que podem ser fontes de sofrimento para as pessoas" (Martins et al., 2014, p. 19).
Ao citar Guanaes e Japur (2003), os autores recobram que o terapeuta deve "construir relações ou conexões criativas" por meio de um modo de investigação que aquelas denominaram de "poética social". Tal postura investigativa, engajada e permanentemente dialógica, favorece a "ampliação das possibilidades de sentido social".

Em uma relação dialógica, mesmo o terapeuta e o cliente possuindo saberes distintos, ambos, ao se engajarem na constituição de narrativas e ações, são influenciados reciprocamente. Isto subverte o sentido de intervenção, tradicionalmente unidirecional e proveniente daquele detentor do saber, e constitui o senso de competência do profissional ao verificar a eficácia para si e para o outro dos efeitos daquela relação terapêutica. Os autores afirmam que "as nossas intervenções podem ser encaradas como apostas relacionais, candidatas a múltiplos e cambiantes sentidos que, informados por discursos terapêuticos, têm potencial de utilidade no contexto situado de uma dada relação" (Martins et al., 2014, p. 29).

\section{O CONCEITO DE SELF}

No artigo intitulado "Construcionismo Social e Metapsicologia: um diálogo sobre o conceito de self", Guanaes e Japur (2003) realizam detalhada descrição do modo como propostas psicanalíticas e construcionistas têm produzido conceituações sobre self. As autoras enfocam diferenças e expandem a reflexão sobre os modos de se conhecer o que vem a ser o self. Refletem que o construcionismo, por conceber a pessoa como polivocal, coloca o foco sobre funções sociais e políticas como formas de descri- 
ção do self, sendo o construcionismo, portanto, uma epistemologia que favorece a produção de conhecimento sobre o self.

Dentro do construcionismo social, as referidas autoras apresentam o conceito de self sob três enfoques, a saber: (a) a Pessoa como usuária do discurso (Potter \& Wetherell, 1996); (b) a Teoria do Posicionamento (Davies \& Harré, 1999) e (c) self Narrativo (Gergen, 1994).

Conforme Guanaes e Japur (2003), no prisma construcionista, a perspectiva discursiva de Potter e Wetherell versa sobre uma concepção de self estruturada na linguagem, performática, em ação e relacional, que estabelece um estado de dominação e subordinação entre os usuários do discurso. Nesse sentido, a pessoa como usuária do discurso sustenta seus discursos nos recursos sociais, denominados por Potter e Wetherell (1996) e citado pelas autoras como "repertório interpretativo".

Assim, Guanaes e Japur (2003) retomam Edward e Potter (1992) quando estes afirmam que a perspectiva discursiva redefine o conceito de linguagem, bem como o de self. Este "passa a ser entendido como o discurso sobre o self, com uma ênfase particular sobre o que as pessoas fazem de determinados repertórios interpretativos e sobre as funções pragmáticas das descrições de si mesmo".

Por outro lado, as referidas autoras apresentam a Teoria do Posicionamento e recorrem a Davies e Harré (1999) para explicar conceitos centrais desta visão sobre self, que são: "posição, força social da ação e linha de história".

Por "Posição", conforme descrevem Guanaes e Japur (2003, p.139), entende-se os "lugares sociais assumidos e negociados pelas pessoas em suas conversações". "Linha de história", por sua vez, refere-se ao conjunto de significados atribuído à posição negociada, em uma "sequência de coisas já ditas". Por fim, a "força social" diz respeito ao ato de assumir ou atribuir ao outro determinada posição, conforme apresentado pelas autoras.

Guanaes e Japur (2003) descrevem a perspectiva de self Narrativo proposta por Kenneth Gergen (1994). Por narrativo, depreende-se as explicações que as pessoas elaboram para descrever a si mesmas e ao mundo, como organizam suas histórias de forma inteligível a elas e ao mundo e essas narrativas, enquanto recursos conversacionais, são entendidas como construções abertas à contínua alteração na medida em que uma interação progride.

Por fim, Guanaes e Japur (2003, p. 140) acrescentam que, para Gergen (1994), "o self narrativo funciona como histórias orais dentro de uma sociedade, que são usadas como recursos culturais, com diferentes propósitos sociais, podendo ser de auto-identificação, auto-justificação e solidificação social". Dessa maneira, self narrativo vem a ser produto do intercâmbio social, imerso na interdependência, o que evidencia seu caráter social e historicamente situado.

\section{CONCLUSÃO}

Conclui-se que a produção acadêmica referente à Psicoterapia de orientação construcionista social, jovem e quantitativamente modesta no campo acadêmico brasileiro, apresenta profícuo referencial teórico e orientações claras a uma prática clínica relacional, reflexiva, dialógica e capaz de produzir, com recursos linguísticos, múltiplas possibilidades de existência e de realidades. 
Os catálogos virtuais acessados, Biblioteca Virtual de Saúde - Psicologia (BVS-Psi) e Scientific Electronic Library Online (SciELO), permitiram o rastreamento do já escrito sobre o construcionismo social e o intercâmbio entre a produção constituída e esta pesquisa. O emprego dos descritores e a subdivisão da pesquisa em eixos temáticos que fazem parte da proposta metodológica permitiram que se delineasse o caráter descritivo e inventariante deste trabalho ao mapear os artigos que tratam da psicoterapia de orientação construcionista.

$\mathrm{O}$ método de mapeamento usado nesta pesquisa, denominado "Estado da arte" pelo seu caráter bibliográfico, permitiu identificar os trabalhos concernentes aos aspectos teóricos, à clínica e à postura do profissional que ali se posiciona como anfitrião na clínica e convidado na relação com seu cliente, sendo um especialista do processo, e o outro especialista do conteúdo, como afirmam Lenzi et al. (2015).

Visto que possui um discurso não naturalista, ontológico e não universalista sobre os fenômenos humanos, o construcionismo expande o entendimento sobre a realidade, o self e o mundo, ao conceber que é no campo da linguagem, das implicações das práticas discursivas no cotidiano que são produzidos os muitos "eus" e mundos possíveis.

Devido ao seu caráter contextual e histórico, novas descrições sobre o que vem a ser a clínica psicoterápica construcionista social estão sempre por vir, o que garante seu status de movimento e não escola teórica. Nesse sentido, entendemos com Manfrim e Rasera (2016, p.40), ao referencia- rem Holzman e Mendez (2003), que a terapia é performática, pois "diz respeito à noção do ser humano como um ser capaz de criar, manter e transformar sua própria realidade".

Estes autores ainda prosseguem enfatizando que "o fato de sermos performativos permite que nos engajemos em criar diferentes atos de performance, podendo transformar a atividade, a existência social, assim como qualquer contexto em que estejamos inseridos" (Manfrim \& Rasera, 2016 , p.40). Isto favorece aos profissionais da psicologia que utilizam o construcionismo social como ferramenta em sua clínica, uma atuação criativa, crítica, reflexiva e engajada com a história do cliente, convidando-o também a performar.

Neste mapeamento bibliográfico, no que se refere a gama de perspectivas terapêuticas, foi possível identificar tensionamentos resultantes de enfoques distintos na relação terapêutica e alguns distanciamentos, mas, reiterado por todas, busca-se dar ênfase na cultura, na postura crítica, e, fundamentalmente, nos relacionamentos que constroem o mundo e a cada um pela linguagem em ação. Tal conduta coloca o terapeuta em uma posição colaborativa, em que suas intervenções são encaradas como realizações relacionais (Martins et al., 2014).

Diante das considerações acima, espera-se favorecer novos diálogos possíveis por meio de produção de relatos de caso, condução de atendimentos, reflexões teóricas, entre outros, tanto para ampliar o repertório discursivo daqueles que já atuam, como também para ampliar os horizontes daqueles que se aproximam, curiosos por esta perspectiva epistemológica. 


\section{REFERÊNCIAS}

Amaral, A. E. V., Luca, L., Rodrigues, T.C., Leite, C.A., Lopes, F.L., \& Silva, M. A. (2012). Serviços de Psicologia em clínicas-escola: revisão de literatura. Boletim de Psicologia(São Paulo), 62(136), 7-520. Recuperado de http://pepsic.bvsalud.org/pdf/ bolpsi/v62n136/v62n136a05.pdf

Brito, R. M. M. \& Germano, I. M. P. (2013). Terapia narrativa e abordagem colaborativa: contribuições do Construcionismo social para a clínica pós-moderna. Nova Perspectiva Sistêmica, 22(47), 57-73. Recuperado de http://www.revistanps.com.br/ index.php/nps/article/view/7/8

Gergen, K. J. (1985). The social constructionism movement in modern psychology. American Psychologist,40(3), 266-275.

Gergen, K. J. \& Ness, 0. (2016). Therapeutic practice as social construction. In M. O'Reilly et al. (Eds.),The Palgrave Handbook of Adult Mental Health (pp. 502-519). Hampshire: Palgrave MacMillan.

Guanaes, C. \& Japur, M. (2003). Construcionismo social e metapsicologia: um diálogo sobre o conceito de self. Psicologia: Teoria e Pesquisa (Brasília), 19(2), 135-143. Recuperado de http://www.scielo.br/pdf/ptp/v19n2/ a05v19n2

Harper, D. (2004). Introducing social constructionist and critical psychology into clinical psychology training. In G. Lerner \& D. Paré (Orgs.), Collaborative Practice in Psychology and Therapy (pp. 157-170). New York: Haworth Press.

Lenzi, By, Anjos, A.C., Westphal, A.C.g Raffs, K.C., Gonçalves, L., Germani, M. et al. (2015). A construção da postura profissional para o encontro terapêutico. Nova Perspectiva Sistêmica, 24(53), 7-23. Recuperado de http:// www.revistanps.com.br/index.php/ nps/article/view/109/105

Manfrim, A. F. N. \& Rasera, E. F. (2016). Diálogos entre o discurso construcionista social e a terapia social. Nova Perspectiva Sistêmica, 25(56), 34-48. Recuperado de http://pepsic.bvsalud.org/pdf/nps/v25n56/n25a04.pdf Martins, Pr P. S. Santos, C. Pry \& Rasera, E. F. (2013). A terapia focada na solução e suas aproximações ao discurso construcionista social. Estudos de Psicologia (Campinas), 30(1), 111-120). Recuperado de http://dx.doi.org/10.1590/ S0103-166X2013000100012

Martins, P. P. S., Silva, G. M., \& Guanaes-Lorenzi, C. (2014). Os sentidos de uma intervenção e suas implicações para a construção do senso de competência de um terapeuta. Nova Perspectiva Sistêmica (Rio de Janeiro), 23(50), 18-31. Recuperado de http:// www.revistanps.com.br/index.php/ nps/article/view/89/80

Mirim, L. Y. L. (2004). Garimpando sentidos em bases de dados. In M. J. Spink (Org.), Práticas discursivas e produção de sentidos no cotidiano: aproximações metodológicas (3a ed., pp. 153-181). São Paulo: Cortez.

Paula-Ravagnani, G. S., Guanaes-Lorenzi, C., \& Rasera, E. F. (2017). Use of theoretical models in family therapy: Focus on social constructionism. Paidéia (Ribeirão Preto), 27(67), 84-92. Recuperado de http://dx.doi. org/10.1590/1982-43272767201710

Rasera, E. F. \& Japur, M. (2004) Desafios da aproximação do construcionismo social ao campo da psicoterapia. Estudos de Psicologia (Natal), 9(3), 431439. Recuperado de http://www.scielo.br/pdf/epsic/v9n3/a05v09n3.pdf

Romanowski. J. P. \& Eens. R. T. (2016). As pesquisas denominadas do tipo "estado da arte" em educação. Revista Diálogo Educacional (Curitiba), 
6(6), 37-50. Recuperado de http:// www.file:///C:/Users/User/Downloads/dialogo-237\%20(1).pdf

Rosas, E. V. \& Rapizo, R. (2011). Construcionismo social e a formação de terapeutas: em busca de coerência. Nova Perspectiva Sistêmica, 20(41), 54-64. Recuperado de http://www. revistanps.com.br/index.php/nps/ article/viewFile/205/186

Shotter, J. (1993). Conversational realities: constructing life trough language. London: Sage.

Spink, M. J. \& Medrado, B. (2013). Produção de Sentido no cotidiano. In M. J. Spink (Org.), Práticas discursivas e produção de sentidos no cotidiano: aproximações metodológicas(pp.22-41). São Paulo: Cortez.

Spink, Pr, Ribeiro, M. A. Ta, Conejo, S. Pry \& Souza, E. (2014) Documentos de Domínio Público e a produção de informações. InM. J. P. Spink, J. I. M. Brigagão, V. L. V. Nascimento, \& M. P. Cordeiro (Orgs.), A produção de informação na pesquisa social: compartilhando informações (pp. 207 -228). Rio de Janeiro: Centro Edelstein de Pesquisas Sociais.

Vosgerau, D. S. A. R. \& Romanowski, J. P. (2014). Estudos de revisão: implicações conceituais e metodológicas. Revista Diálogo Educacional, 14(41), 165-189. Recuperado de https://periodicos.pucpr.br/index. php/dialogoeducacional/article/ view/2317

Winslade, J. \& Monk, G. (2016). Mediação narrativa: uma abordagem diferenciada para a resolução de conflitos. Nova Perspectiva Sistêmica (Rio de Janeiro), 25(54), 7-16. Recuperado de http://www.revistanps.com.br/ index.php/nps/article/view/99/121
TAFFAREL RAMIRES FERNANDES

(https://orcid.org/0000-0002-8804-2816)

É graduando em Psicologia pelo Centro Universitário FIPMoc, Montes Claros, MG, Brasil.

E-mail: taffarelrf@yahoo.com.br

\section{VINÍCIUS AMARANTE NASCIMENTO}

(https://orcid.org/0000-0003-0129-850X) É graduado e mestre em História, graduando em Direito pela Universidade Estadual de Montes Claros/MG.

E-mail: viniciusamarantenascimento@ gmail.com

gnail.com 